\title{
Dopamine correlates of neurological and psychological status in untreated Parkinsonism ${ }^{1}$
}

\author{
MARGARET M. HOEHN, T. J. CROWLEY, AND C. O. RUTLEDGE \\ From the Departments of Neurology, Psychiatry, and Pharmacology, \\ University of Colorado Medical Center, Denver, Colorado, USA
}

SYNOPSIS Thirty-seven untreated Parkinsonism patients showed significant positive correlations among decreased excretion of free dopamine, MMPI scores indicative of schizophrenic-like looseness of thinking, and the severity of all Parkinsonism signs except tremor. The data could indicate that abnormalities of dopamine metabolism may underlie both the motor and mental abnormalities of Parkinsonism.

James Parkinson (1817) specifically noted that 'the senses and intellects' are not altered in the syndrome now bearing his name. However, there have been subsequent observations (Hoehn and Yahr, 1967; see Brown and Wilson, 1972) of both dementia and disturbances of affect in patients with Parkinsonism. Levita et al. (1964) reported that intellectual ability deteriorates as rigidity increases. The motor abnormalities of Parkinsonism are related to the degeneration of dopamine-containing neurones in the nigrostriatal pathway of the brain (Carlsson, 1959; Ehringer and Hornykiewicz, 1960; Birkmayer and Hornykiewicz, 1961). Dopamine (DA) may be involved also in complex behavioural abnormalities, such as schizophrenia (Carlsson and Lindqvist, 1963; Kalant, 1966; Nybäck et al., 1968; Janowsky et al., 1973; Matthysse, 1973; Snyder et al., 1974).

This is a study of the relationships between the severity of motor and psychological abnormalities in untreated Parkinsonism patients. The amount of free (unconjugated) DA in the urine was used as an index of dopaminergic activity. Many peripheral sources contribute more to urinary DA than does the central nervous system. But, whatever the sources, urinary levels of free DA are low in Parkinsonism patients (Barbeau et al., 1961; Bischoff and Torres, 1962; Weil-Malherbe and Van Buren, 1969; Kott et al.,

\footnotetext{
'Supported by US Public Health Service-National Institutes of Health Grant NS 09199 and Grant (RR-51) from the General Clinical Research Program of the Division of Research Resources, National Institutes of Health.

Present address: Department of Pharmacology and Toxicology, School of Pharmacy, University of Kansas, Lawrence, Kansas 66045, USA.

(Accepted 16 June 1976.)
}

1971). A small decrease in the level of free DA in the urine, therefore, may reflect the known deficiency of DA in the neurones of the brain in Parkinsonism (Ehringer and Hornykiewicz, 1960; Hornykiewicz, 1974).

\section{METHODS}

All 37 patients had classical signs of Parkinsonism; none had clinical evidence of corticospinal, cerebellar, or sensory pathology. Twenty-eight patients had primary Parkinsonism, or Parkinson's disease; the others had secondary Parkinsonism (not druginduced). The 18 men and 19 women were between 30 and 82 years old (mean $65.7 \pm$ SEM 10.8 years). Parkinsonism had been present for two to 36 years (mean $8.7 \pm 9.5$ years). Patients had not been treated with anti-Parkinsonism medications for at least one week before initial evaluation. All received diets free of catecholamines in hospital during, and for three days before, evaluations.

Signs of Parkinsonism were graded on a scale of increasing severity from 0 to 4 (Yahr et al., 1969). The maximal deficit score is 100 ; tremor contributes a possible 20 , rigidity 20 , akinesia 44 , and other phenomena of Parkinsonism 16. Patients also were classified by stage of disease and functional impairment (Hoehn and Yahr, 1967): stage I, unilateral involvement; stage II, bilateral involvement; stage III, impairment of balance and postural righting reflexes, but still independent in all activities of daily living; stage IV, severe disease, requiring help in activities of daily living; stage $\mathrm{V}$, confined to bed or wheelchair unless aided. 
Patients completed the Minnesota Multiphasic Personality Inventory (MMPI) and the Multiple Affect Adjective Checklist (MAACL). The MMPI is a general personality test standardised with both medical and psychiatric populations (Dahlstrom and Welsh, 1960). The MAACL is a test of affect; the patient chooses mood-related adjectives (happy, sad, etc) which apply to him on the day of the examination, and the test is scored for anxiety, depression, and hostility (Zuckerman and Lubin, 1970).

Collections of urine started at 6 a.m.; all voidings during the next 24 hours were added immediately to one bottle containing $2.0 \mathrm{~g}$ sodium metabisulphite and stored at $4^{\circ} \mathrm{C}$ until the end of the collection. Samples were then frozen and stored at $-5^{\circ} \mathrm{C}$. Two or more assays were done of the free and of the total (free plus conjugated) forms of each metabolite in each sample of urine. Dopamine and its major catechol metabolite, 3,4-dihydroxyphenylacetic acid (DOPAC), were extracted by alumina chromatography, and DA in the alumina eluates was measured by the dihydroxyindole fluorometric procedure (Anton and Sayre, 1964). DOPAC was further isolated by paper chromatography and measured fluorometrically (Sourkes et al., 1963). Homovanillic acid (HVA), the major O-methylated metabolite of DA, was assayed by a modification of the procedure of Sato (1965; see Rutledge and Hoehn, 1973) and later by the procedure of Vidi and Bonardi (1972). The latter procedure involves ethyl acetate extraction of HVA from acidified urine samples, thin layer chromatography of the extracts, conversion of HVA to a fluorescent derivative, and measurement of the derivative by spectrophotofluorometry. Total amounts of the metabolites were measured by the same methods after the urine was boiled in hydrochloric or sulphuric acid (Weil-Malherbe, 1968) to hydrolyse the conjugates. The urinary content of each of the metabolites was corrected for recovery. The recoveries were (mean \pm SEM): DA $76.0 \pm 4.0 \%$; DOPAC $54.6 \pm 2.7 \%$; HVA $74.0 \pm 4.7 \%$.

Neurological and psychiatric evaluations were repeated after one year of treatment with L-dopa.

\section{RESULTS}

\section{NEUROLOGY}

The mean pretreatment neurological scores ( + SEM) were: tremor $5.1 \pm 3.7$; rigidity $9.4 \pm 4.1$; akinesia $24.9 \pm 8.9$; total neurological deficit $45.7 \pm 14.9$. Seven patients were at stage II, and 17 at stage III. Thirteen of the 37 patients were severely disabled at stages IV and V.

\section{PSYCHIATRY}

Twenty-five patients completed the MMPI and MAACL; the others were too impaired to take the tests. The mean MMPI profile for the group is shown in Fig. 1. Scales 2(Depression), 8 (Schizophrenia), and 1 (Hypochondriasis) were most elevated. The mean score on Welsh's Anxiety Index (AI, not shown; Dahlstrom and Welsh, 1960) is 70.8 ( \pm 3.9 SEM). The Goldberg Index (Goldberg, 1965) was calculated for each patient (scores on MMPI Scales $\mathrm{L}+6+8-3 \mathrm{C}$ $-7)$. Five patients fell in the 'neurotic' range of Goldberg scores under $40 ; 13$ were in the psychoticrange of scores over 49; and seven were in the indeterminant range of $40-49$. In 14 patients, the MMPI Scale 8/Scale 7 ratio (Heaton and Victor, 1976) was greater than 1. The Goldberg Index and the 8/7 ratio, measures of loose, psychotic-like thinking, correlated with one another $(r=0.48, \mathrm{P}<0.02)$. Mean MAACL scores $( \pm$ SEM) were Anxiety $51 \pm 2.7$; Depression

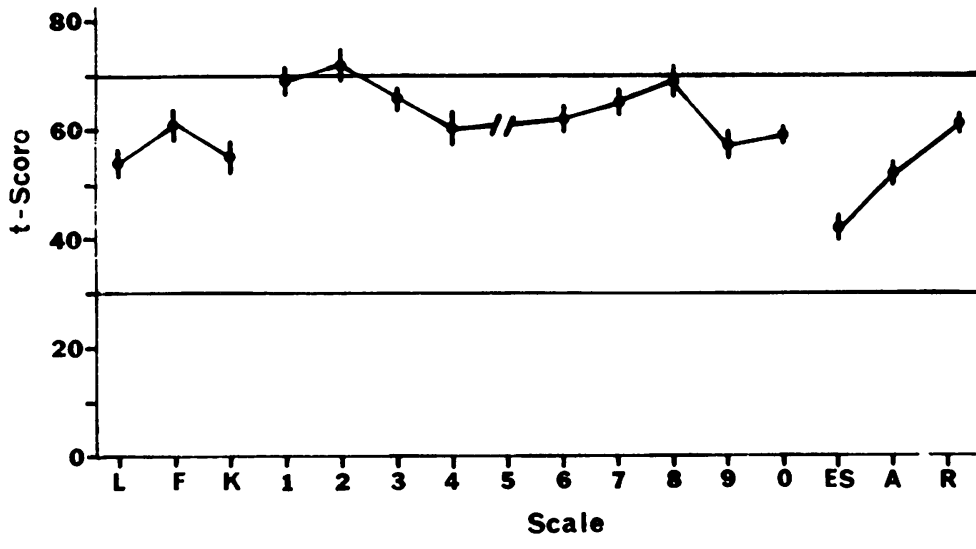

FIG. 1 Mean MMPI profile: mean scores $\pm S E M$ for each scale of the MMPI of 25 untreated patients with Parkinsonism. 
$47 \pm 2.3$; and Hostility $42 \pm 2.1$. There were no significant differences by $t$ test on any scale of the MMPI or MAACL between the 19 patients with primary Parkinsonism and the six with secondary Parkinsonism.

\section{BIOCHEMISTRY}

The urinary excretion of DA, DOPAC, and HVA in 27 patients with primary Parkinsonism was not significantly different from the excretion in the five with post-encephalitic disease or from that in the entire group of patients with secondary Parkinsonism (Table 1). In the urine of patients with primary Parkinsonism, $85.4 \%$ of DA was present as a conjugate; $79.7 \%$ of DOPAC, and only $25.9 \%$ of HVA, was conjugated.

\section{NEUROLOGY AND PSYCHIATRY}

The Pearson product-moment correlations between neurological impairment and psychological test scores are shown in Table 2. As akinesia increased, Ego Strength fell, and several MMPI scales indicating psychopathology increased: Schizophrenia, Anxiety, Depression, Psychasthenia, Hypochondriasis, and Paranoia. The correlation between akinesia and MMPI-8 Scale (Schizophrenia) was the highest encountered in this study between a psychological test score and any neurological or biochemical variable. Rigidity had fewer psychological concomitants than akinesia; as rigidity increased, the Anxiety Index and Scales 7 (Psychasthenia) and 8 (Schizophrenia) increased, while Ego Strength and K (both of which measure a tendency to speak favourably of oneself) decreased. Total neurological deficit and stage of functional impairment correlated positively with several of these measures of psychopathology. Conversely, increasing tremor was not associated with increases of any measure of psychopathology. Duration of illness and sex of patient (not shown in
Table 2) did not correlate with any psychological scores.

\section{NEUROLOGY AND BIOCHEMISTRY}

The excretion of free DA correlated negatively with the severity of rigidity and akinesia $(\mathrm{P}<0.025)$ and with the total neurological deficit score $(P<0.05)$ (Table 3). There was no significant correlation between free dopamine and the severity of tremor. The only other correlation was the positive relationship between free DOPAC and tremor.

\section{PSYCHIATRY AND BIOCHEMISTRY}

Urinary free DA correlated negatively $(\mathrm{P}<0.025)$ with Scale 8 (Schizophrenia) (Table 4). The Scale 8/Scale 7 ratio and the Goldberg Index correlated significantly and negatively with urinary free DA respectively, $r=-0.47$ and $-0.34 ; \mathrm{P}<0.02$ and $<0.05$ ); these two correlations do not appear in Table 4. HVA and total free metabolites negatively correlated with several measures of psychopathology, especially scales 6 (Paranoia) and 9 (Mania), together with scale Ip (Index of Psychopathology), which is mathematically derived from scales 6 and 9 (Sines and Silver, 1963). The three scales of the MAACL did not correlate with levels of urinary DA or its metabolites.

INTERCORRELATIONS OF NEUROLOGY, PSYCHIATRY, AND BIOCHEMISTRY

Of the numerous pretreatment biochemical, neurological, and psychological variables assessed in these patients, 44 were cross-correlated (a $44 \times 44$ Pearson product-moment correlation matrix) and submitted to a factor analysis (Varimax rotated factor matrix, after rotation with a Kaiser normalisation) (Table 5). The analysis yielded 11 factors above an Eigen value of 1 . Each of the last five factors accounted for $6 \%$ or

T A B L E 1

URINARY DA, DOPAC, AND HVA IN PARKINSONISM PATIENTS

\begin{tabular}{|c|c|c|c|c|c|c|c|}
\hline \multirow[b]{2}{*}{ No. of } & \multirow[b]{2}{*}{ Diagnosis } & \multicolumn{2}{|c|}{$D A$} & \multicolumn{2}{|c|}{$D O P A C$} & \multicolumn{2}{|c|}{$H V A$} \\
\hline & & Free & Total & Free & Total & Free & Total \\
\hline 28 & $\begin{array}{l}\text { Primary Parkinsonism } \\
\text { Secondary Parkinsonism }\end{array}$ & $149+23$ & $1024 \pm 284$ & $512+100$ & $2554 \pm 259$ & $2844 \pm 366$ & $3837 \pm 477$ \\
\hline 5 & Encephalitis lethargica & $152 \pm 38$ & $735+179$ & $342+130$ & $1716 \pm 519$ & $2062+617$ & $3077 \pm 577$ \\
\hline 2 & Supranuclear palsy & 245 & 526 & 330 & 1032 & 614 & 1475 \\
\hline 1 & ? Huntington's disease & 93 & 181 & 511 & 1270 & 2949 & 2820 \\
\hline 1 & Carbon monoxide & 302 & 1091 & 472 & 1649 & 326 & 373 \\
\hline
\end{tabular}

Values are expressed as mean $\pm S E M \mu g / 24$ hour urine samples. 
TA B LE 2

CORRELATIONS OF NEUROLOGICAL IMPAIRMENT AND PSYCHOLOGICAL TEST SCORES

\begin{tabular}{|c|c|c|c|c|c|}
\hline Scale & Tremor & Rigidity & Akinesia & $\begin{array}{l}\text { Total } \\
\text { neuro } \\
\text { deficit }\end{array}$ & Stage \\
\hline \begin{tabular}{ll} 
MMPI \\
L & Lie \\
F & Fake \\
K & \\
1 & Hypochondriasis \\
2 & Depression \\
3 & Hysteria \\
4 & Psychopathic \\
6 & Paranoia \\
7 & Psychasthenia \\
8 & Shizophrenia \\
9 & Mania \\
0 & Social introversion \\
ES & EgoStrength \\
A & Anxiety \\
AI & Anxiety Index \\
R & Repression \\
Ip & Index of \\
\multicolumn{1}{|c}{ Psychopathology }
\end{tabular} & -.342 & $\begin{array}{r}-.426^{*} \\
.468 \dagger \\
.440^{*}\end{array}$ & $\begin{array}{r}-.437^{*} \\
.433^{*} \\
.465 \dagger\end{array}$ & $\begin{array}{r}-.431^{*} \\
.411^{*} \\
.441^{*}\end{array}$ & $\begin{array}{l}.412^{*} \\
.499+\end{array}$ \\
\hline $\begin{array}{l}\text { MAACL } \\
\text { A Anxiety } \\
\text { D Depression } \\
\text { Hostility }\end{array}$ & & & $\begin{array}{l}.369 \\
.475 \dagger\end{array}$ & .371 & .361 \\
\hline
\end{tabular}

All, and only, values for which $P<0.05$ are listed.

${ }^{*} \mathrm{P}<0.025$.

$\dagger \mathbf{P}<0.01$.

T A B LE 3

CORRELATIONS OF NEUROLOGICAL IMPAIRMENT AND URINARY DOPAMINE METABOLITES

\begin{tabular}{|c|c|c|c|c|c|}
\hline & Tremor & Rigidity & Akinesia & $\begin{array}{l}\text { Total } \\
\text { neuro } \\
\text { deficit }\end{array}$ & Stage \\
\hline $\begin{array}{l}\text { Dopamine, free } \\
\text { Dopamine, total } \\
\text { DOPAC, free } \\
\text { DOPAC, total } \\
\text { HVA, free } \\
\text { HVA, total } \\
\text { All metabolites, free } \\
\text { All metabolites, total }\end{array}$ & .307 & $-.327^{*}$ & $-.357^{*}$ & -.288 & \\
\hline
\end{tabular}

All, and only, values for which $P<0.05$ are listed

${ }^{*} \mathrm{P}<0.025$.

less of the total variance; they are not shown in Table 5.

Factor 1 is composed entirely of MMPI variables. Severity of psychopathology on any one of these scales correlated with severity of psychopathology on the others. The only negative correlations in this factor are Ego Strength and K, which typically decrease as emotional disturbance increases.

Factor 2 consists entirely of biochemical measures.
The correlations were uniformly positive. Total DA and conjugated DA were strong determinants of this factor, loading above the 0.900 level; free DA contributed less powerfully.

Factor 3, unlike the first two, is not a readily predictable set of intercorrelations among obviously related variables. It indicates that patients excreting less free DA tended to have more severe akinesia, rigidity, and total neurological deficit; on the MMPI- 
T A B L E 4

CORRELATIONS OF URINARY DOPAMINE METABOLITES AND MMPI SCORES

\begin{tabular}{|c|c|c|c|c|c|c|c|c|c|}
\hline & & \multicolumn{2}{|c|}{$D A$} & \multicolumn{2}{|c|}{$D O P A C$} & \multicolumn{2}{|c|}{$H V A$} & \multicolumn{2}{|c|}{$\begin{array}{c}\text { Total } \\
(D A+\text { metabolites })\end{array}$} \\
\hline & & Free & Total & Free & Total & Free & Total & Free & Total \\
\hline L & $\begin{array}{l}\text { Lie } \\
\text { Fake }\end{array}$ & & .363 & & & & & & \\
\hline 1 & Hypochondriasis & & & & & & & & \\
\hline 2 & Depression & & & & & & & & \\
\hline 3 & Hysteria & & & & & -.354 & & -.384 & \\
\hline 4 & Psychopathic & & & & & & & & \\
\hline 6 & Paranoia & & & & & $-.410^{*}$ & -.384 & $-.415^{*}$ & \\
\hline 7 & Psychasthenia & & & & & & & & \\
\hline 8 & Schizophrenia & $-.397 *$ & & & & & & & \\
\hline 9 & Mania & & & & & $-.438^{*}$ & -.377 & $-.430^{*}$ & \\
\hline 0 & Social Introversion & & & .360 & & & & & \\
\hline ES & EgoStrength & & & & & & & & \\
\hline A & Anxiety & & & & & & -.356 & & \\
\hline AI & Anxiety Index & & & & & & -.363 & & \\
\hline $\mathbf{R}$ & Repression & & & & & & & & \\
\hline Ip & Index of Psychopathology & & & & & & $-.449 *$ & -.372 & $-.420^{*}$ \\
\hline
\end{tabular}

All, and only, values for which $P<0.05$ are listed.

${ }^{*} \mathrm{P}<0.025$.

8 Scale, performance tended to resemble that of schizophrenic patients. Tremor was absent from this factor, suggesting that severity of tremor was related neither to the severity of akinesia nor of rigidity, nor to urinary levels of DA.

Factor 4 is mainly internal positive correlations of MAACL scores, with women scoring higher than men. Factor 5 suggests that patients with severe tremor may obtain a better therapeutic response to levodopa than those with severe functional impairment (neurological Stage). Factor 6 shows that the excretion of DA metabolites was greater in men than women; this is not a function of body weight.

\section{EVALUATION AFTER L-DOPA THERAPY}

Twenty-one patients completed MMPIs at least one year after the original studies. During this time they were treated only with L-dopa and had been stabilised for at least six months on individualised maximally therapeutic dosages (mean $=4.7 \mathrm{~g} /$ day). There was significant improvement, clinically and statistically $(\mathrm{P}<0.005)$, in each neurological parameter (Fig. 2). However, there was essentially no change in the MMPI scores (Fig. 3); only the Ego Strength Scale changed significantly $(\mathrm{P}<0.05)$, and it became worse.

\section{DISCUSSION}

\section{NEUROLOGY AND PSYCHIATRY}

The mean MMPI profile (Fig. 1) was similar to those of other Parkinsonism groups (Beardsley and Puletti,
1971; Marsh and Markham, 1973). Pre-treatment personality measures were increasingly pathological in proportion to the severity of all signs of Parkinsonism except tremor (Table 2). Akinesia was the most malignant, correlating with all three scales of anxiety (MMPI scales A and AI, MAACL scale A), both scales of depression (MMPI-2 and MAACL-D), the Schizophrenia Scale (MMPI-8), the Index of Psychopathology (MMPI-Ip), and several other scales. The correlation between Schizophrenia (MMPI-8) and akinesia was the highest between any psychological and any neurological or biochemical variable. In non-psychiatric populations, elevations on scale 8 reflect social alienation, peculiarity, and interpersonal distance-schizoid characteristics.

The correlation of anxiety with akinesia and rigidity is of clinical interest. High scores on MMPI-A are produced (Dahlstrom and Welsh, 1960) by hesitant, inhibited, overcontrolled people, who are slow in response, speech, movement, and general tempo; they frequently are unemotional, apathetic, and 'fussy'. These attributes are compatible with the appearance and behaviour of many Parkinsonism patients. On the other hand, low scorers on MMPI-A are described as energetic, enthusiastic, forceful and sociable, traits missing from most rigid, akinetic patients with Parkinsonism

Therapy with L-dopa improved the neurological status of these patients (Fig. 2) but did not produce concomitant improvement of their psychopathology (Fig. 3). 
T A B LE 5

FACTOR ANALYSIS OF NEUROLOGICAL, PSYCHOLOGICAL, AND BIOCHEMICAL CORRELATIONS

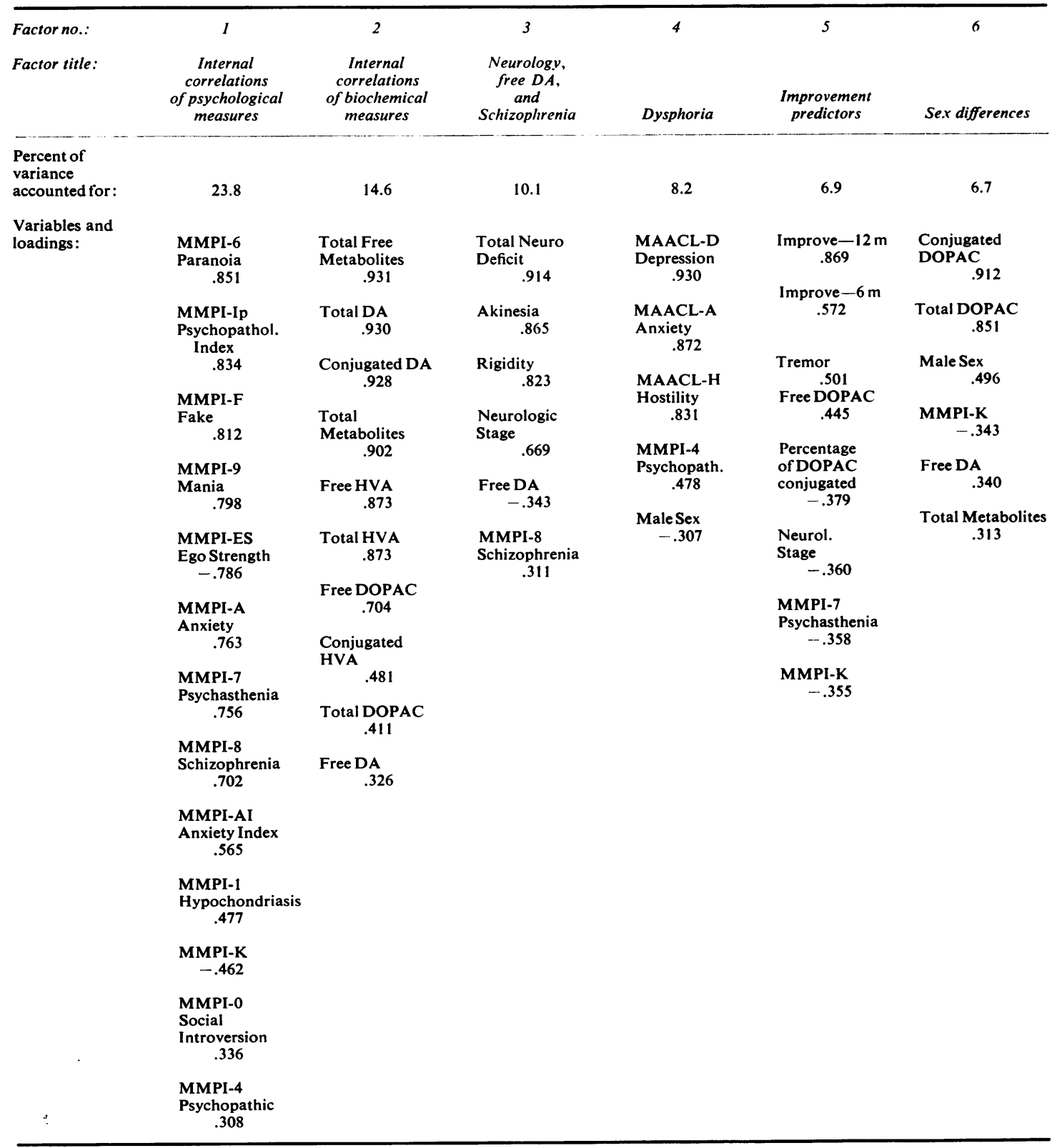

All, and only, values loading over .300 are listed. 


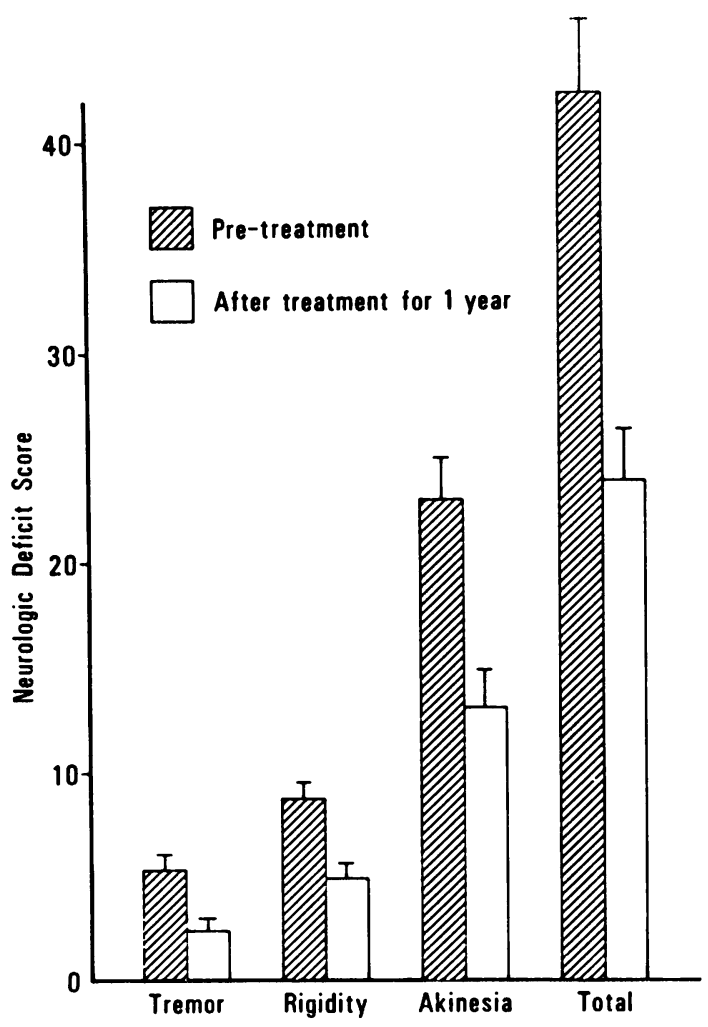

FIG. 2 Mean neurological deficit scores of 21 patients before and after one year of treatment with L-dopa.

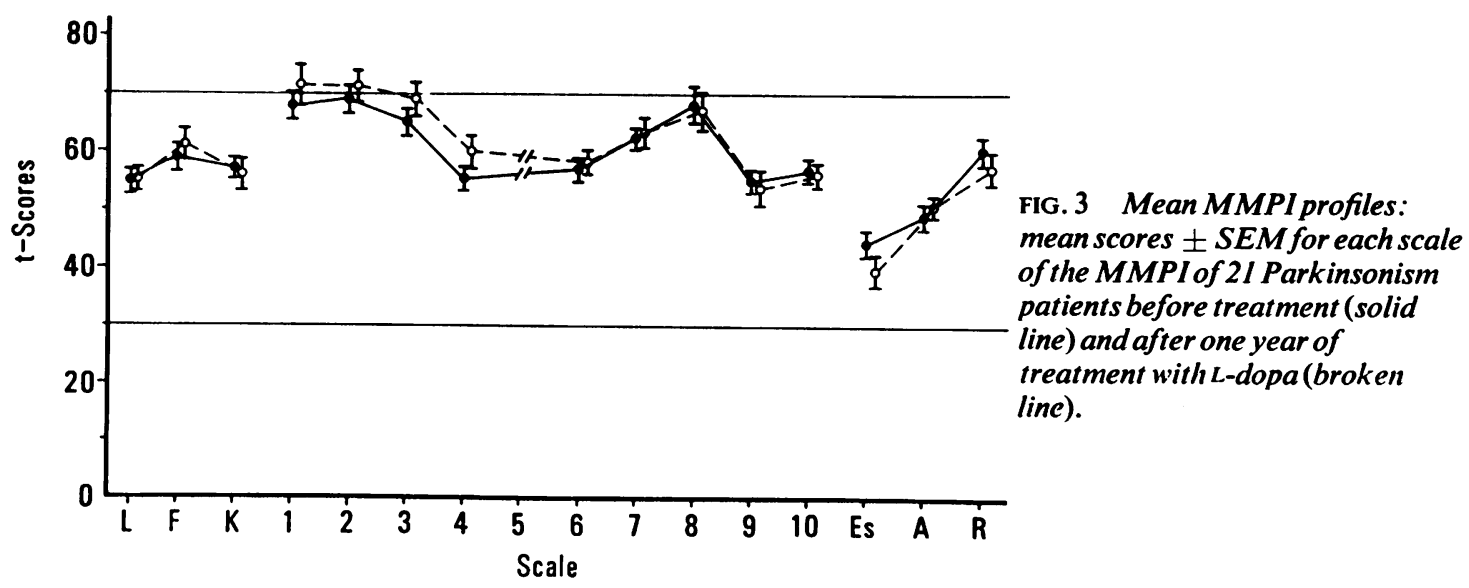




\section{NEUROLOGY AND BIOCHEMISTRY}

Although there is considerable evidence that free DA is excreted in reduced quantities in patients with Parkinson's disease (Barbeau et al., 1961; Bischoff and Torres, 1962; Barbeau, 1969a; Weil-Malherbe and Van Buren, 1969, Kott et al., 1971), correlations between the severity of disease and the degree of DA deficiency are less well established. Deficiencies of DA and HVA in the nigrostriatal complex in the brain do correlate with the severity of akinesia (Hornykiewicz, 1974). With regard to urinary levels of DA, Barbeau (1969a) found that Parkinsonism patients with akinesia as the predominant symptom excreted less DA than did an unselected group of Parkinsonism patients.

In our patients, the lower the level of free DA in the urine, the more severe were rigidity, akinesia, and neurological and functional deficit; the strength of these correlations is surprising. In the rat only a small proportion of urinary DA appears to derive from brain (Hoeldtke et al., 1974). The correlations which we find between a CNS function (neurological impairment) on the one hand, and urinary dopamine excretion on the other, may have resulted from any of several causes: increased motor activity among our patients may have resulted in increased urinary DA arising from peripheral sources. Another possibility is that free DA from peripheral sites could be a relatively constant constituent of urine, with changes in urinary DA excretion mainly reflecting changes in CNS dopamine metabolism. This seems unlikely. A third possibility, suggested by Barbeau (1969a), is that Parkinsonism is a 'systemic' disease; he has demonstrated altered DA uptake in the platelets of Parkinsonism patients (Barbeau et al., 1975). If Parkinsonism patients have a generalised disorder of DA metabolism, urinary excretion of free DA, although it is primarily of peripheral origin, may accurately reflect the severity of the disturbance in central dopamine metabolism.

Tremor did not correlate with low levels of urinary DA, the other signs of Parkinsonism, or the psychological abnormalities. Other clinical, therapeutic, pathological, and experimental reports have suggested that the tremor of Parkinsonism differs from the akinesia and rigidity (Owen and Marsden, 1965; Stadlan et al., 1965; Yahr et al., 1968; Barbeau, 1969b Cotzias, et al., 1969; Godwin-Austin et al., 1969; Abramsky et al., 1971; Hornykiewicz, 1971; Chase et al., 1973; Strian et al., 1972; Lloyd et al., 1973). This study adds evidence that Parkinsonian tremor may have clinical and neurochemical concomitants different from those of rigidity and akinesia.
PSYCHIATRY AND BIOCHEMISTRY

The higher the MMPI-8 (Schizophrenia) scores, the lower were the levels of free DA in the urine; this was the only significant correlation $(P<0.025)$ in Table 4 for either MMPI-8 or free DA. MMPI-8 usually indicates tenuous thinking, deficient in its relatedness to external conditions. But the MMPI- 8 sometimes is elevated without clear evidence for 'loose' or psychotic thought. Heaton and Victor (1976) argue that the scale $8 /$ scale 7 ratio is a better measure of 'looseness' of thought than is scale 8 alone. In this study, the correlation of scale $8 /$ scale 7 with urinary free DA was even stronger than the dopamine-to-scale 8 correlation. The Goldberg Index appears to be the best MMPI indicator of a psychotic diagnosis (Goldberg, 1965). Over half of our patients produced 'psychotic' MMPIs by this measure, and the Goldberg Index also correlated significantly and negatively with free DA. The preponderance of other negative correlations in Table 4 suggests that, in our Parkinsonism patients, increasing psychopathology in general, and especially loose, schizophrenic-like thinking, was associated with diminished excretion of DA and its metabolites.

Disordered DA metabolism may play a role in some severe psychiatric syndromes. Schizophrenic patients have been reported to excrete less free DA than normal controls (Mattock et al., 1967). By the probenecid-HVA test (van Pragg and Korf, 1971; Bowers, 1974), patients with retarded depressions and those with poor-prognosis schizophrenia show evidence in the cerebrospinal fluid of reduced central turnover of DA. These findings might suggest decreased dopaminergic activity in schizophrenic patients. On the other hand, Carlsson and Lindqvist (1963) speculated that the effectiveness of phenothiazines in the treatment of schizophrenia was the result of blockade of DA receptors, suggesting that DA neurones may be hyperactive in schizophrenia. This hypothesis is supported by several observations: the degree of DA receptor blockade by several phenothiazines is positively correlated with their therapeutic efficacy (see Snyder et al., 1974). Antipsychotic drugs also inhibit electrically-stimulated release of DA from slices of rat striatum; the potency with which these drugs inhibit DA release correlates with the average daily dosage of the drugs used in the treatment of schizophrenia (Seeman and Lee, 1975). Amphetamine, which releases DA from neurones, produces in overdose a psychosis similar to that of schizophrenia (Kalant, 1966), and small doses of an amphetamine-like compound, given to schizophrenic patients, exacerbate the symptoms of the disease (Janowsky et al., 1973). Thus, a considerable body of evidence relates schizophrenic illnesses to abnormali- 
ties of DA metabolism. However, the exact nature of these abnormalities remains unclear.

INTERCORRELATIONS OF NEUROLOGY, PSYCHIATRY, AND BIOCHEMISTRY

It is unlikely that spurious factors produced the intercorrelations of psychological with biochemical and neurological data in this study:

1. Dementia, for example, is associated with Parkinson's disease (Brown and Wilson, 1972) and might produce confused responses to the MMPI and artefactual elevations of scale 8. However, the 'validity' scales, $L$ and $F$, which increase with confused responding, did not correlate with neurological or biochemical abnormalities, making it unlikely that the scale 8 elevation was due only to confusion. The relationship of the Schizophrenia scale to akinesia, rigidity, and DA deficiency thus appears to be at least partly independent of a dementing process.

2. It also seems unlikely that the elevation of scale 8 was only a psychological response to loss associated with medical illness; increasing depression is the common response to loss, and the development of schizoid traits would be unusual. In this study, depression did indeed correlate significantly with the severity of the neurological signs (Table 2). However, it did not correlate with the urinary DA deficiency (Table 4). The Schizophrenia Scale correlated with both the DA deficiency and the neurological signs. The scale 8/scale 7 ratio and the Goldberg Index correlated negatively with the DA level but not with the neurological findings. Thus, unlike the depressive response to the symptoms, the schizoid characteristics may be more directly associated with the deficiency of DA.

3. The follow-up examinations of the patients also indicate that the personality characteristics were not just psychological responses to the losses associated with physical illness. After L-dopa treatment the neurological scores fell by nearly half; if the personality characteristics were due to a psychological response to physical illness, they might have been expected to improve. Instead, the personality characteristics were very stable, scarcely changing at all.

Our data show a relationship between urinary free DA levels and both akinesia and MMPI evidence of loose, schizoid thinking. The akinesia improved with L-dopa therapy, but the MMPIs showed no consistent change. These findings may be variously interpreted. Akinesia could result in reduced peripheral DA release, thus decreasing the urinary free DA. Presumably, then, the akinesia and the MMPI characteristics would both be of central origin, while the DA excretion would be a peripheral epiphenomenon of altered motility. Since the akinesia, but not the MMPI characteristics, improve with L-dopa therapy, the neurological and psychiatric signs would assumedly be mediated by different central mechanisms. Alternatively, Parkinsonism might be a 'systemic' disease with the well-known motor signs, impairment of central and peripheral DA metabolism, and certain centrally-determined personality characteristics. In either case, we would view the personality characteristics as originating from CNS pathology. Their failure to improve as the motor signs improved with therapy suggests that the personality characteristics are not mere psychological responses to the symptoms of the disease.

Clinically, these patients show Parkinsonism, not schizophrenia. But both Parkinsonism and schizophrenia are reportedly associated with a decrease in the central turnover rate of DA (Bowers, 1974; Chase, 1974). Vogt (1973) wrote that 'it is fairly evident that the neurons involved in the antipsychotic effect (of phenothiazine drugs) are not those of the nigrostriatal pathway, the destruction of which in Parkinsonism neither protects from, nor predisposes to, schizophrenia; if we assume that the therapeutic effect is mediated by dopaminergic neurons, they must lie outside the nigrostriatal pathway'. Although our data indicate that increasing severity of signs of Parkinsonism may be associated with increasingly schizophrenic-like personality characteristics, the two diseases obviously are not equivalent, and the neuropathology of each presumably involves pathways other than the nigrostriatal. However, our findings that schizoid characteristics and the neurological impairment develop conjointly in Parkinsonism patients adds to the growing evidence for some relationship between the two conditions.

The authors wish to thank Dr Donald Stilson and Ms Marilyn Hydinger for statistical advice, Ms Amelia Marlowe and Mr Robert Arnold for technical help, Ms Linda Greco-Sanders for secretarial assistance, and the staff of the Clinical Research Center for their cooperation in these studies.

\section{REFERENCES}

Abramsky, O., Carmon, A., and Lavy, S. (1971). Combined treatment with propranolol and levodopa.Journal of the Neurological Sciences, 14, 491-494.

Anton, A. H., and Sayre, D. F. (1964). The distribution of dopamine and dopa in various animals and a method for their determination in diverse biological material. Journal of Pharmacology and Experimental Therapeutics, 145, 326-336.

Barbeau, A. (1969a). Parkinson's disease as a systemic disorder. In Third Symposium on Parkinson's Disease, pp 
66-73. Edited by F. J. Gillingham and I. M. L. Donaldson. Livingstone: Edinburgh.

Barbeau, A. (1969b). L-dopa therapy in Parkinson's disease: A critical review of nine years' experience. Canadian Medical Association Journal, 101, 791-800.

Barbeau, A., Campanella, G., Butterworth, R. F., and Yamadu, K. (1975). Uptake and efflux of ${ }^{14} \mathrm{C}$-dopamine in platelets: Evidence for a generalized defect in Parkinson's disease. Neurology (Minneap), 25, 1-9.

Barbeau, A., Murphy, G. F., and Sourkes, T. L. (1961). Excretion of dopamine in diseases of basal ganglia. Science (Washington), 133, 1706-1707.

Beardsley, J. V., and Puletti, F. (1971). Personality (MMPI) and cognitive (WAIS) changes after levodopa treatment: occurrence in patients with Parkinson's disease. Archives of Neurology (Chic.), 25, 145-150.

Birkmayer, W., and Hornykiewicz, O. (1961). Der L-3,4-Dioxyphenylalanin (=Dopa)-Effekt bei der Parkinson-Akinese. Weiner Klinische Wochenschrift, 73, 787-788.

Bischoff, F., and Torres, A. (1962). Determination of urine dopamine. Clinical Chemistry, 8, 370-377.

Bowers, M. B. (1974). Central dopamine turnover in schizophrenic syndromes. Archives of General Psychiatry, 31, 50-54.

Brown, G. L., and Wilson, W. P. (1972). Parkinsonism and depression. Southern Medical Journal, 65, 540-545.

Carlsson, A. (1959). The occurrence, distribution, and physiological role of catecholamines in the nervous system. Pharmacological Reviews, 11,490-493.

Carlsson, A., and Lindqvist, M. (1963). Effect of chlorpromazine or haloperidol on formation of 3-methoxytyramine and normetanephrine in mouse brain. Acta Pharmacologia et Toxicologica, 20, 140-144.

Chase, T. N. (1974). Catecholamine metabolism and neurologic disease. Biochemical Pharmacology, 23, suppl., 941-946.

Chase, T. N., Ng, L. K. Y., and Watanabe, A. M. (1973). Parkinson's disease: modification by 5-hydroxytryptophan. Neurology (Minneap.), 22, 479-484.

Cotzias, G. C., Papavasiliou, P. S., and Gellene, R. (1969). Modification of parkinsonism-chronic treatment with L-dopa. New England Journal of Medicine, 280, 377-345.

Dahlstrom, W. G., and Welsh, G. S. (1960). An MMPI Handbook: A Guide to Use in Clinical Practice and Research. University of Minnesota Press: Minneapolis.

Ehringer, H., and Hornykiewicz, O. (1960). Verteilung von Noradrenalin und Dopamine (3-Hydroxytyramin) im Gehirn des Menschen und ihr Verhalten bei Erkrankungen des extrapyramidalen Systems. Klinische Wochenschrift, 38, 1236-1239.

Goldberg, L. R. (1965). Diagnosticians vs diagnostic signs: the diagnosis of psychosis $v s$ neurosis from the MMPI. Psychological Monographs, 79, 1-28.

Godwin-Austen, R. B., Tomlinson, E. B., Frears, C. C., and Kok, H. W. L. (1969). Effects of L-dopa in Parkinson's disease. Lancet, 2, 165-168.
Heaton, R. K., Victor, R. G. (1976). Personality characteristics associated with psychedelic flashbacks in natural and experimental settings. Journal of Abnormal Psychology (In press).

Hoehn, M. M., and Yahr, M. D. (1967). Parkinsonism: onset, progression, and mortality. Neurology (Minneap.), $17,427-442$.

Hoeldtke, R., Rogawski, M., and Wurtman, R. J. (1974). Effect of selective destruction of central and peripheral catecholamine-containing neurones with 6-hydroxydopamine on catecholamine excretion in the rat. British Journal of Pharmacology, 50, 265-270.

Hornykiewicz, O. (1971). Histochemistry, biochemistry, and pharmacology of brain catecholamines in extrapyramidal syndromes in man. In Monoamines Noyaux Gris Centraux et Syndrome de Parkinson, pp. 143-157. Edited by J. de Ajuriaguerra and G. Gauthier. Georg: Geneva.

Hornykiewicz, O. (1974). Metabolism of dopamine and L-dopa in human brain. Biochemical Pharmacology, 23, suppi., 917-923.

Janowsky, D. S., El-Yousef, M. K., Davis, J. M., and Sekerke, H. J. (1973). Provocation of schizophrenic symptoms by intravenous administration of methylphenidate. Archives of General Psychiatry, 28, 185-191.

Kalant, O. J. (1966). The Amphetamines. Thomas: Springfield, Ill.

Kott, E., Bornstein, B., and Eichhorn, F. (1971). Excretion of dopa metabolites. New England Journal of Medicine, 284, 395 .

Levita, E., Riklan, M., and Cooper, I. S. (1964). Cognitive and perceptual performance in Parkinsonism as a function of age and neurological impairment. Journal of Nervous and Mental Diseases, 139, 516-520.

Lloyd, K. G., Davidson, L., and Hornykiewicz, O. (1973). Metabolism of levodopa in the human brain. In $A d-$ vances in Neurology, vol. 3. Raven Press: New York.

Marsh, G. G., and Markham, C. H. (1973). Does levodopa alter depression and psychopathology in Parkinsonism patients? Journal of Neurology, Neurosurgery, and Psychiatry, 36, 925-935.

Matthysse, S. (1973). Antipsychotic drug actions: a clue to the neuropathology of schizophrenia. Federation Proceedings, 32, 200-205.

Mattock, G. L., Wilson, D. L., and Hoffer, A. (1967). Catecholamine metabolism in schizophrenia. Nature, 213, 1189-1190.

Nybäck, H., Borzecki, Z., and Sedvall, G. (1968). Accumulation and disappearance of catecholamines formed from tyrosine- ${ }^{14} \mathrm{C}$ in mouse brain: effect of some psychotropic drugs. European Journal of Pharmacology, 4,395-403.

Owen, D. A. L., and Marsden, C. D. (1965). Effect of adrenergic $\beta$ blockade on parkinsonian tremor. Lancet, 2, 1259-1262.

Parkinson, J (1817). Essay on the Shaking Palsy. Sherwood, Neely, and Jones: London. 
Rutledge, C. O., and Hoei!n, M. M. (1973). Sulphate conjugation and L-dopa treatment of parkinsonian patients. Nature. 244, 447-450.

Satu, T. L. (1965). The quantitative determination of 3-methoxy-4-hydroxyphenylacetic acid (homovanillic acid) in urine. Journal of Laboratory and Clinical Medicine, 66, 517-525.

Seeman, P., and Lee, T. (1975). Antipsychotic drugs: Direct correlation between clinical potency and presynaptic action on dopamine neurons. Science (Washington), 188, 1216-1219.

Sines, L., and Silver, R. (1963). An index of psychopathology derived from clinicians' judgements of MMPI profiles. Journal of Clinical Psychology, 19, 324-326.

Snyder, S. H., Banerjee, S. P., Yamamura, H. I., and Greenberg, D. (1974). Drugs, neurotransmitters and schizophrenia. Science (Washington), 184, 1243-1253.

Sourkes, T. L., Denton, R. L., Murphy, G. F., Chavez, B., and Saint Cyr, S. (1963). The excretion of dihydroxyphenylalanine, dopamine, and dihydroxyphenylacetic acid in neuroblastoma. Pediatrics, 31, 660-668.

Stadlan, E. M., Duvoisin, R., and Yahr, M. D. (1965). The pathology of parkinsonism. In Proceedings of the Fifth International Congress of Neuropathology, pp. 569-571. Edited by F. Luthy and A. Bischoff. International Congress Series No. 100, Excerpta Medica: Amsterdam.

Strian, F., Micheler, E., and Benkert, O. (1972). Tremor inhibition in parkinson syndrome after apomorphine administration under L-dopa and decarboxylase in- hibitor basic therapy. Pharmakopsychiatrie NeuroPsychopharmakologie, 5, 198-205.

van Pragg, H. M., and Korf, J. (1971). Retarded depression and the dopamine metabolism. Psychopharmacologia, 19, 199-203.

Vidi, A., and Bonardi, G. (1972). Simple quantitative method for determining 3-methoxy-4-hydroxyphenylacetic acid in urine. Clinica Chimica Acta, 38, 463-464.

Vogt, M. (1973). Functional aspects of the role of catecholamines in the central nervous system. British Medical Bulletin, 29, 168-171.

Weil-Malherbe, H. (1968). The estimation of total (free and conjugated) catecholamines and some catecholamine metabolites in human urine. Methods of Biochemical Analysis, 16, 293-326.

Weil-Malherbe, H., and Van Buren, J. M. (1969). The excretion of dopamine and metabolites in Parkinson's disease and the effect of diet thereon. Journal of Laboratory and Clinical Medicine, 74, 305-318.

Yahr, M. D., Duvoisin, R. C., Hoehn, M. M., Schear, M. J., and Barrett, R. E. (1968). L-dopa-its clinical effects in parkinsonism. Transactions of the American Neurological Association, 93, 56-63.

Yahr, M. D., Duvoisin, R. C., Schear, M. J., Barrett, R. E., and Hoehn, M. M. (1969). The treatment of parkinsonism with levodopa. Archives of Neurology (Chic.), 21, 343-354.

Zuckerman, M., and Lubin, B. (1970). Bibliography for Multiple Affect Adjective Checklist. Educational and Testing Service: San Diego, California. 